\title{
False Convictions and True Conscience ${ }^{\dagger}$
}

\author{
Candice Delmas*
}

\begin{abstract}
Society typically shows conscientious objectors more deference than civil disobedients, on the grounds that they appear more conscientious and less strategically minded than the latter. Kimberley Brownlee challenges this standard picture in Conscience and Conviction: The Case for Civil Disobedience, where she claims that civil disobedience is more conscientious than conscientious objection, in virtue of its communicativeness. Brownlee conceives of conscientious conviction as necessarily communicative, and distinguishes it from 'conscience'-the set of practical moral skills involved in adequately responding to complex situations. This review article argues that Brownlee's account of conviction is too narrow, as it excludes many core beliefs which we would want to classify as convictions although they violate one or more of the criteria of communicativeness, while her account of conscience is incomplete, because it ignores some of the persistent obstacles for the development of conscience produced by structural injustice. The article identifies these obstacles and offers some strategies for protecting against them, namely, vigilance, self-scrutiny, empathy and collaborative ambivalence.
\end{abstract}

Keywords: conscience, conviction, communication, civil disobedience, conscientious objection

\section{Introduction}

'A crime is a crime is a crime, it is not political', stated then UK Prime Minister Margaret Thatcher in 1980, standing firm against the Irish republican prisoners who had staged a hunger strike to protest against the British government's revocation of their POW-like Special Category Status. ${ }^{1}$ Underlying this stance

* Assistant Professor of Philosophy, Clemson University. Email: cdelmas@clemson.edu. I thank Kimberley Brownlee for her comments on a previous draft of this essay; and I am especially grateful to Julie Dickson for her extensive editorial suggestions and substantive feedback.

${ }^{\dagger}$ A review of K Brownlee, Conscience and Conviction: The Case for Civil Disobedience (OUP 2012).

${ }^{1}$ Quoted in P O'Malley, Biting at the Grave: The Irish Hunger Strikes and the Politics of Despair (Beacon Press 1990) 60.

(C) The Author 2015. Published by Oxford University Press. All rights reserved. For permissions, please e-mail: journals.permissions@oup.com 
and that statement is the refusal, common among public officials, to distinguish between ordinary criminal offending and conscientious practices such as civil disobedience and conscientious objection. Yet civil disobedients and conscientious objectors alike act from steadfast moral or political commitments, whereas criminals do not and are typically narrowly self-interested.

Civil disobedients are sometimes treated well by police and courts. Here are three examples involving the arrest, prosecution, and trial of environmental activists who had resorted to civil disobedience. First, at a protest against the Vermont Yankee nuclear plant in 2012, the police arrested 130 environmental activists 'calmly and without any confrontation, with obvious signs that protesters and police had worked out the logistics beforehand', according to reporters. ${ }^{2}$ Second, a Massachusetts district attorney recently dropped the criminal charges brought against two environmental activists who had blocked a coal shipment. ${ }^{3}$ Third, 44 Vermonters who waged a sit-in in a Senator's office in protest of his support of the US Government's policy of selling arms to Nicaraguan contras were ultimately acquitted by a jury on a 'necessity defence'. ${ }^{4}$

These cases of accommodation and perhaps even leniency by the state, however, are the exception rather than the rule. ${ }^{5}$ Police often use lawenforcement weapons such as batons and teargas against peaceful protesters (most recently in Ferguson, MO). District attorneys rarely drop criminal charges against civil disobedients; and judges generally make pre-trial determinations that juries will not hear evidence of necessity in protest cases. ${ }^{6}$ Civil disobedients are thus generally treated as common criminals by states' governments, and sometimes even found to be more dangerous than common criminals. The 1969 US Report of the Task Force on Law and Law Enforcement to the National Commission on the Causes and Prevention of Violence,

\footnotetext{
${ }^{2}$ See eg W Ring, 'Vermont Yankee Protest: 130 Demonstrators Arrested At Nuclear Plant's Corporate Headquarters' Huffington Post (23 March 2012) <www.huffingtonpost.com/2012/03/23/vermont-yankee-protest_ n_1374451.html> accessed 1 October 2014.

${ }^{3}$ See eg D Abel, 'Bristol DA Drops Charges, Says Protesters were Right' Boston Globe (8 September 2014) $<$ www.bostonglobe.com/metro/2014/09/08/activists-drops-charges-case-blocked-coal-shipment-power-plant/ sUpBpGxzxAz3E2Vr5RFQQM/story.html> accessed 1 October 2014.

${ }^{4}$ See B Bradley and N Wasserman (eds), Por Amor Al Pueblo: Not Guilty! (Front Porch 1986). The jurors found that the protesters undertook their illegal sit-in in last resort, after other means of protest had been exhausted. Note, however, that this happened in 1984, five years before the US Ninth Circuit articulated the evidentiary requirements that must be met before defendants may present the necessity defence to a jury. To wit, the defendant must prove: '(1) that he was faced with a choice of evils and chose the lesser evil; (2) that he acted to prevent imminent harm; (3) that he reasonably anticipated a causal relation between his conduct and the harm to be avoided; and (4) that there were no other legal alternatives to violating the law'. United States v Aguilar 883 F 2d 662, 693 ( $9^{\text {th }}$ Cir 1989). Even if the 44 Vermonters could have met the fourth prong of necessity, they would likely have failed the other three.

${ }^{5}$ For a discussion of the norms and practices that should guide the state's response to civil disobedients, see W Smith, Civil Disobedience and Deliberative Democracy (Routledge 2013) ch 5. William Smith articulates an original 'philosophy of accommodation' focused on negotiation and dialogue with protest groups.

${ }^{6}$ See n 4; JL Cavallaro, Jr, 'The Demise of the Political Necessity Defense: Indirect Civil Disobedience and United States v Schoon' (1993) Cal L Rev 351; J A Cohan, 'Civil Disobedience and the Necessity Defense' (2007) Pierce L Rev 111.
} 
for instance, vilified anti-war and civil rights protests as posing dangerous threats to social order. ${ }^{7}$

In contrast, conscientious objectors benefit from some substantial protections and are often exempt from complying with rules and orders that conflict with their moral conscience. For instance, the German Constitution provides that 'No person shall be compelled against his conscience to render military service involving the use of arms'. 8 Most countries that provide reproductive healthcare services such as contraception and abortion have enacted 'conscience clauses' to grant healthcare professionals the right to conscientiously refuse to provide such services. ${ }^{9}$ Forty-eight states in the US permit parents to refuse to immunise their children for 'nonmedical' reasons, on the basis of religious belief; and twenty states among those, including California, Texas, and Michigan, permit exemptions based on nonreligious personal convictions. ${ }^{10}$ This kind of deference toward conscientious objection is usually justified by appeal to the respect owed to individuals' conscientiousness and the recognition of the moral and psychic burdens of complying with law that goes against one's beliefs.

But if civil disobedience and conscientious objection are both conscientious practices, why do they receive such a different treatment? Conscientious objection tends to be seen as more conscientious than civil disobedience and its psychic burdens as heavier, so that it is deemed to have an overall greater claim to protection. Thus John Rawls contrasts civil disobedients, who are organised into groups, with conscientious objectors, who typically act alone, and further notes that unlike civil disobedients, who intend to address the majority through their disobedient act, and think strategically about the best ways to communicate their message, the conscientious objector does not set out to engage with others, and in fact hopes that the necessity to disobey will not arise. ${ }^{11}$ In these ways, conscientious objection appears more modest or less 'showy' than civil disobedience. The difference can be illustrated by the contrast between Martin

${ }^{7}$ Law and Order Reconsidered; Report of the Task Force on Law and Law Enforcement to the National Commission on the Causes and Prevention of Violence, A staff report prepared by JS Campbell and JR Sahid per Executive Order \#11412 <http://archive.org/stream/laworderreconsid00camprich/laworderreconsid00camprich_djvu.txt $>$ accessed 1 October 2014.

${ }_{8}$ Article 4(3) of the German Constitution.

${ }^{9}$ The use of conscientious objection in reproductive health care is prevalent, for instance, in Italy, Poland, Slovakia, the US, Mexico, and South Africa. See eg C Zampas and X Andión-Ibañez, 'Conscientious Objection to Sexual And Reproductive Health Services: International Human Rights Standards and European Law And Practice' (2012) 19 Eur J Health Law 231; L Casas, 'Invoking Conscientious Objection in Reproductive Health Care: Evolving Issues in Peru, Mexico and Chile' (2009) 17 Reprod Health Matters 78; VM Lema, 'Conscientious Objection and Reproductive Health Service Delivery in Sub-Saharan Africa' (2012) 16 Afr J Reprod Health 15.

${ }^{10}$ See N Berlinger, 'Conscience Clauses, Health Care Providers, and Parents' in M Crowley (ed), From Birth to Death and Bench to Clinic: The Hastings Center Bioethics Briefing Book for fournalists, Policymakers, and Campaigns (The Hastings Center 2008) 35-40.

11 Rawls defines conscientious refusal as 'noncompliance with a more or less direct legal injunction or administrative order' and civil disobedience as 'a public, nonviolent, conscientious yet political act contrary to law usually done with the aim of bringing about a change in the law or policies of the government'. J Rawls, $A$ Theory of Fustice (revised edn, Harvard University Press 1999) 320, 323. 
Luther's 'here I stand, I can do no other'12 and Martin Luther King, Jr's 'how can we bring Birmingham to her knees?.' ${ }^{13}$

In her rich and thought-provoking new book Conscience and Conviction: The Case for Civil Disobedience, ${ }^{14}$ Kimberley Brownlee reverses the standard liberal picture laid out above. She revisits the concept of 'conscientiousness' (or, as Brownlee calls it in the book, 'conviction') to highlight the features that make conscientious acts of disobedience worthy of protection, and argues that civil disobedience is in fact more conscientious than conscientious objection. Brownlee demonstrates this through a detailed analysis of the two core concepts that give the book its title-conscience and conviction.

Brownlee elucidates the concept of 'conviction' in the first chapter. 'Conviction', also referred to as 'conscientious conviction' and 'conscientiousness', is a descriptive property that designates sincerely held, though possibly erroneous, 'communicative' moral commitment. When we have a conscientious conviction that something is wrong, on Brownlee's view, we must (a) avoid the conduct in question to the best extent that we are able; (b) judge such conduct in others to be wrong as well; and we must be willing (c) to bear the risks of honouring our conviction; as well as (d) to communicate the reasons that we think justify our conviction to others. These four elements-consistency, universality, non-evasion, and dialogue-form the core of the 'communicative principle of conscientiousness'. ${ }^{15}$

The second chapter conceives of the concept of 'conscience' as a normative property that characterises 'a set of practical moral skills that stem from an inward knowledge of the workings of our own mind and heart. ${ }^{16}$ Brownlee situates conscience within a pluralistic moral framework, so that its function is not to 'give objectively right answers to moral questions,' but it is instead to 'help us to privilege certain values over others in light of our personal moral situation' ${ }^{17}$ Having conscience, on Brownlee's account, involves being genuinely responsive to complex moral situations, that is, properly appreciative of the legitimacy of the different values in play.

This brief overview of Brownlee's analysis already hints toward what, in Brownlee's view, is wrong with the standard picture: first, civil disobedience, insofar as it is essentially communicative, displays more conscientiousness than

\footnotetext{
12 'Hier stehe ich und kann nicht anders!' Source: <www.luther.de/legenden/ws.html> accessed 1 October 2014.

${ }^{13}$ Though not a direct quote, this question captures King's reasoning at various points during the 1963 Birmingham Campaign, which included lunch counter sit-ins, store boycotts, marches and the famous 'Children's Crusade'. See eg 'Birmingham Campaign (1963)', King Institute Encyclopedia <http://mlk-kpp01. stanford.edu/index.php/encyclopedia/encyclopedia/enc_birmingham_campaign/> accessed 1 October 2014.

${ }^{14} \mathrm{~K}$ Brownlee, Conscience and Conviction: The Case for Civil Disobedience (OUP 2012) (hereinafter referred to as Brownlee).

15 ibid 29-46.

16 ibid 52 .

17 ibid 10 .
} 
conscientious objection; second, the guide for moral action is conscience, not conscientiousness. Let me briefly explain each point.

First, the 'conviction argument', as Brownlee calls it, challenges the idea that private, non-communicative acts of conscientious objection are more 'conscientious' than suitably constrained, communicative acts of disobedience such as civil disobedience. Civil disobedience, in her view, is a 'deliberate breach of law taken on the basis of steadfast personal commitment in order to communicate our condemnation of a law or policy to a relevantly placed audience'. ${ }^{18}$ Hence it is necessarily public and communicative, whereas conscientious objection does not involve a deliberate breach of law and is not necessarily communicative. ${ }^{19}$ Brownlee thus re-labels conscientious objection 'personal disobedience' in order to underscore the generally private nature of its manifestation and eliminate the connotation of superior conscientiousness. Since civil disobedience is an essentially communicative practice, it is more conscientious-and thus more genuine-than personal disobedience, in Brownlee's view. Moreover, insofar as efforts to engage with others about our deep commitments through open and constrained law-breaking are more worthy of protection than private and evasive acts of disobedience, Brownlee argues that civil disobedience deserves more protection than personal disobedience does.

Second, we often confuse conscientious conviction and conscience, in part because the concepts are cognates, but also because our convictions feel to us to be animated by conscience. Yet Brownlee claims that these properties are different: in her view, to repeat, conviction is a descriptive property of sincerely held core moral beliefs that abide by the four-pronged principle of communicativeness; and conscience is a normative property that characterises the practical wisdom involved in adequately responding to complex situations. Brownlee stresses that although conviction often motivates us to act, it does not necessarily result in our acting morally, since our deep moral commitments may be erroneous, misguided, or even unjustifiable. Instead, it is conscience, with its apparatus of practical moral skills, that we ought to nurture. The 'conscience argument', elaborated in chapter 2 of the book, claims that conscience (once we cultivate it to a sufficient degree) enables us to perceive our moral responsibilities, ie the demands morality makes on us in virtue of our moral roles, and to honour them.

Brownlee goes on to develop in the third chapter a series of arguments designed to explain how and why formal expectations and moral responsibilities conflict (the 'gap thesis'), why we ought to adhere to our moral responsibilities at the expense of the formal dictates of our office (the 'moral roles thesis') and even at the expense of our all-things-considered moral duties

\footnotetext{
18 ibid 18.

19 ibid 27.
} 
(the 'priority of special responsibility thesis'), and what the implications are for society (the 'minimum moral burdens principle').

In the fourth chapter, Brownlee discusses whether or not there is a moral right to engage in personal and civil disobedience. She finds that conscience generates a substantial moral right that protects our ability to honour our special moral responsibilities, free from interference. In contradistinction, conscientious conviction generates two limited moral rights: one to inner control and free thought (the right is limited insofar as it does not protect us from others' interference with our attention); the other to conscientious action. This latter right to conscientious action protects many acts of civil disobedience in virtue of their communicativeness, but not generally acts of personal disobedience, given their evasiveness. Although all these moral rights have a bearing on how upholders of the law should operate, neither of them carries an automatic presumption in favour of being established as legal right.

While chapters 1-4 are grouped under the heading 'Morality', the second part of the book, comprised of chapters 5-8, focuses on 'Law'. Chapters 5 and 6 argue in favour of two legal defences that are not currently available to civil disobedients, but should be. The first one, which Brownlee calls the 'demandsof-conviction defence', is an excusatory defence that is grounded in respect for autonomy and recognition of the psychological costs of literal adherence with law when it conflicts with our commitments. This defence tracks conscientious moral conviction and is more available to public, communicative acts of civil disobedience than it is to personal disobedience. The other is the necessity defence, which already exists in the law, but is not generally accepted as a defence for civil disobedients. ${ }^{20}$ Per Brownlee's proposal, the necessity defence is a justificatory defence that is grounded in recognition of the centrality of non-contingent basic needs, and tracks conscience-driven, responsibilityprioritising, morally responsive acts of civil disobedience.

Chapters 7 and 8 articulate a theory of punishment to accommodate the foregoing account of civil disobedience. Chapter 7 defends, contra Anthony Duff's monistic communicative theory, a pluralistic communicative theory of punishment that is sensitive to offenders' communicative efforts. ${ }^{21}$ The eighth and final chapter of the book argues, contra David Lefkowitz's account of the moral right to civil disobedience which includes a claim-right against punishment but not against penalisation, that civil disobedients have a moral right against punishment, penalisation, prevention, and formal or symbolic censure. $^{22}$ Though this right is not absolute, Brownlee suggests that the reasons to respect it recommend a non-punitive restorative approach that clearly distinguishes civil disobedients from ordinary offenders.

\footnotetext{
${ }^{20}$ See nn 4 and 6.

21 See A Duff, Punishment, Communication, and Community (OUP 2001).

22 See D Lefkowitz, 'On a Moral Right to Civil Disobedience' (2007) 117 Ethics 202.
} 
Brownlee offers in the second part of the book an original and nuanced approach to the treatment of civil disobedients inside and outside the courtroom, that is not only rightly sensitive to offenders' communicative efforts, but also in natural accord with liberal societies' professed respect for individuals' conscience. In this review, however, I shall mainly focus on the concepts of conviction and conscience as they are articulated in the first two chapters of the book. These concepts indeed provide the groundwork upon which Brownlee builds her theory, so that the soundness of the conviction argument depends on the correctness of Brownlee's communicative conception of conscientiousness, while the soundness of the conscience argument rests on the accuracy of her characterisation of conscience. Given these concepts' foundational status, it is especially important to submit them to scrutiny.

As I shall argue, however, the narrowness of one and the incompleteness of the other threaten Brownlee's arguments. In the next section, 'Convictions', I show that Brownlee's conception of conviction in terms of communicativeness is problematically narrow because it excludes many core beliefs which we would want to classify as conscientious convictions although they run afoul of one or more of the conditions of the communicative principle. In section 3, 'Conscience', I argue that Brownlee's account of conscience is incomplete and propose to remedy its lacunae by identifying some of the persistent obstacles for the cultivation of conscience, especially those produced by structural injustice, and setting forth several strategies for developing conscience against these obstacles.

\section{Convictions}

\section{A. Communicativeness}

We ordinarily understand conscientious conviction to refer to sincere, though not necessarily communicative, core moral belief. Brownlee's own definition of conviction is at odds with this ordinary understanding, as she claims that the marks of communicativeness - to repeat, consistency (we must align our beliefs and actions with our conviction); universality (we must judge other people's conduct by our conviction's lights); non-evasion (we must not evade the potential costs of honouring our conviction); and dialogue (we must engage with others about the reasons for our belief) - are 'necessary and sufficient conditions for conscientious conviction'. ${ }^{23}$ The analysis of conviction in terms of communicativeness is central to the conviction argument, according to which civil disobedience is more conscientious than personal disobedience. Brownlee notes that the conviction argument is animated by 'respect for persons as reasoning and feeling beings who are capable of forming deep,

23 ibid 40. 
persistent moral commitments'. ${ }^{24}$ Given this broad concern for persons' moral capacities, it is surprising that she goes on to defend such a narrow conception of conscientious conviction. Indeed we would intuitively classify as conscientious convictions certain moral beliefs that violate the principle of communicativeness.

Here are some examples. The left-wing political anarchist may both pay her taxes and usually refrain to express or defend her views, because of the risks of honouring her conviction, even in liberal societies (since, for instance, the US Federal Bureau of Investigation designates anarchists as a domestic terrorism threat). ${ }^{25}$ At the extreme, Soviet Russian dissidents could neither act consistently with their convictions nor engage others about them on pain of being sent to the gulag for 'political rehabilitation'. A devout young Catholic convinced that sex outside marriage is morally wrong might still engage in all sorts of intimate physical contact short of coitus, in violation of the consistency condition. A person raised in a very conservative environment might be evasive and non-dialogic as she comes to shed her parents' and peers' views and develops liberal conscientious convictions. ${ }^{26}$ Or again, a 'pro-life' supporter may decline to pass judgment on women who underwent or plan to have an abortion, thereby violating the universality requirement.

Of course, more would need to be said to establish conclusively that these cases constitute strong counterexamples to Brownlee's conception of conscientiousness, but they should, at least, highlight its narrowness, and raise doubts regarding the necessary and sufficient conditions for conviction. Her account indeed seems to draw arbitrary lines amidst the wide array of conscientious beliefs and to neglect the importance of assessing each conviction in its particular milieu. Brownlee examines an impressive list of objections against each component of the communicative principle, anticipating many issues that my examples above purport to raise. However, I do not believe that her responses, which boil down to an emphasis on the principle's contextsensitivity and its supposed malleability to diverse circumstances, lay to rest the various concerns raised by my counterexamples.

Brownlee underscores the fact that the consistency condition is qualified by the clause 'to the best extent we are able', which accommodates physical, psychological, or circumstantial inability. ${ }^{27}$ She stresses that the non-evasion condition 'is of course broadly context sensitive', and that we don't have to honour our beliefs at every single opportunity, or at the risk of offending our

\footnotetext{
24 ibid 17.

25 See US Department of Justice, 'Today's FBI: Facts and Figures 2013-2014', 34 <http://www.fbi.gov/ stats-services/publications/todays-fbi-facts-figures/facts-and-figures-031413.pdf $>$.

${ }^{26}$ Alon Harel critiques Brownlee's conception of conscientious conviction along those lines in his recent review of her book, as he argues that moral beliefs that one is busy reflecting upon and experimenting with are often non-communicative in some ways because of their relative inchoateness. See A Harel, 'Review of Kimberley Brownlee's Conscience and Conviction: The Case for Civil Disobedience' 2013.02.29 Notre Dame Philosophical Reviews <http://ndpr.nd.edu/news/37833> accessed 24 December 2014.

${ }^{27}$ Brownlee 31.
} 
friends and relatives. ${ }^{28}$ Brownlee also considers the objection, nestled in the cases of the left-wing anarchist, the Russian dissident and the budding liberal, that the dialogic condition can often involve significant personal costs, especially for those who hold unpopular views or are disadvantaged in some way.

In her responses to these objections, Brownlee notes the communicative principle's sensitivity to the 'burdens of vulnerability, disadvantage, unpopularity, relative power, and relative cost of communication'. ${ }^{29}$ She denies that the dialogic condition demands we engage with others about our conviction: instead, the condition 'requires that we appreciate the reasons to communicate our conviction and ceteris paribus that we intend to do so unless the reasons to communicate are outweighed by undue costs of communicating, ${ }^{30}$ If I understand Brownlee correctly, it is possible for a conviction to meet the non-evasion and dialogic criteria of communicativeness without ever being actually communicated, so long as the agent appreciates the reason to engage with others but (reasonably) deems the costs of doing so excessively burdensome.

This possibility raises two serious issues for Brownlee's conception of conscientiousness: first, it defeats the point of the communicativeness of conscientious conviction, which is to guarantee that the sincerity of our commitments be visible to all, and that no doubt be cast on it. If convictions can bear the marks of conscientiousness without being communicated, then we have to guess the agent's degree of emotional and psychological investment in his or her belief without relying on its external expression. This seems to remove much of the force and point from Brownlee's principle specifically as a principle of communicativeness. Second, if under certain unfavourable conditions, the criteria of communicativeness can be satisfied notwithstanding the lack of de facto communication, then surely we are justified in wondering why Brownlee claims they are necessary and sufficient conditions for conscientiousness. Conceiving of the communicative principle's conditions as merely sufficient conditions or ceteris paribus constraints instead would better fit its context-sensitivity.

\section{B. Consistency}

In this section, I shall further support my case against Brownlee's conception of conviction by focussing on the following precondition for consistency (and thus for conscientiousness): convictions must meet certain logical and evidentiary standards. As Brownlee explains, 'this does not mean that convictions must be correct, but it does mean that they must meet minimal standards of

\footnotetext{
28 ibid 37.

29 ibid 44.

30 ibid 43.
} 
intelligibility, internal coherence, and evidential satisfactoriness'. ${ }^{31}$ Without minimal intelligibility, consistency, and responsiveness to evidence, Brownlee claims, 'there is no determinate answer to what the content of the conviction is, and hence no way of assessing consistency, and no way of deciding whether and how to be accommodating of it'. ${ }^{32}$ She later adds that irrational convictions 'cannot claim the degree of toleration that genuine conviction can claim because they lack both the determinate content and reflection that confirm our psychological and emotional investment'. ${ }^{33}$

Brownlee thereby seems to exclude from the category of conscientious conviction a significant portion of religious beliefs-especially those based on revelation and grounded in faith-insofar as their veracity to believers is not grounded in, or responsive to, what we usually regard as evidence. ${ }^{34}$ This is problematic given the prominent place of religion in people's life and in their conscientious convictions. It further appears wrong to correlate psychic investment with reflection, when many revelation-based convictions are characterised by a profound psychological and emotional investment that does not necessarily result from reasoned reflection (indeed reflection could either threaten or deepen this investment).

However, Brownlee denies that her account necessarily rules out revelationbased convictions, noting that the consistency and dialogic conditions can be met so long as the person gives (or can give) a reasoned defence of her view. ${ }^{35}$ Brownlee's examples of beliefs that violate this precondition for consistency are parents' belief in healing their sick child through prayer alone and anti-abortion activists' beliefs that they ought to kill abortion providers. ${ }^{36}$ Brownlee does not dwell on any borderline cases, nor does she provide any example of convictions that some people might deem irrational although they do in fact meet minimal standards of evidence. However, she elsewhere mentions refusal of vaccination and opposition to emergency contraceptive pills in a way that implies that these beliefs can be properly classified as convictions. ${ }^{37}$ Another example of conviction that would certainly meet Brownlee's consistency test is Jehovah's Witnesses' refusal of blood transfusion. ${ }^{38}$

But why would the belief that one can heal diabetes through prayer or that one ought to slay physicians who perform abortion violate minimal evidentiary

${ }^{31}$ ibid 31.

32 ibid.

33 ibid 40.

${ }^{34}$ For instance, Brian Leiter conceives of religious beliefs as categorical demands that 'do not answer ultimately (or at the limit) to evidence and reasons, as these are understood in other domains concerned with knowledge of the world. Religious beliefs, in virtue of being based on "faith," are insulated from ordinary standards of evidence and rational justification, the ones we employ in both common sense and in science'. See B Leiter, Why Tolerate Religion? (Princeton University Press 2012) p. 34.

35 Brownlee 44.

36 ibid 41 .

37 ibid 28 .

38 Brownlee tacitly agreed, in correspondence with me, that the beliefs mentioned here, though irrational to some, may qualify as conscientious convictions. 
standards, when the beliefs that vaccines cause autism, that blood transfusions amount to 'eating blood', and that contraception is akin to abortion would not? Brownlee claims that the parents' and anti-abortion activists' beliefs are irrational insofar as the parents would take their child to the hospital for a broken bone, and the activists denigrate the life of the abortion provider at the same time as they call for respecting the life of the unborn. Notwithstanding, I fail to grasp any clear difference in consistency between all these beliefs.

On the one hand, none of those beliefs seems particularly responsive to evidence: contraception-including in the form of the 'morning-after' pilldoes not cause an abortion; instead it either inhibits ovulation or interferes with the fertilisation process. Sound scientific research has established that immunisation does not cause autism, and is not an unnecessary and harmful way for big pharmaceutical companies to make profit, to take just two of the many myths about child vaccines. ${ }^{39}$ On the other hand, the beliefs in prayer healing and in killing abortion providers, like the other beliefs mentioned, seem minimally intelligible, in the sense that it is possible to answer the question what the content of the conviction in each case is, and even to defend it. Thus the parent could appeal to the Scriptures and say that God is the only one who can heal diseases, while the anti-abortion murderer could claim to be acting in defence of the innocent babies who were killed and are about to be killed by the physician. ${ }^{40}$

For these reasons, I doubt that there exists a firm yardstick to determine which irrational and erroneous convictions satisfy Brownlee's precondition for consistency and which do not. However, this does not matter when it comes to assessing claims for protections because there is a simple way of explaining why beliefs in prayer healing and anti-abortion violence are not protected. It isn't because they lack in consistency; instead, it is because they inflict harm on unwilling others (namely, the sick dependent who will die without medical intervention and the healthcare provider targeted for murder).

Regardless of whether it meets certain minimal evidentiary standards, a belief does not deserve any respect if it directly results in harming or endangering others (or one might say that the imposition of harm or risk of harm to unwilling others outweighs the conviction's putative claim to protection). And so the pharmacist may refuse to fill a prescription for the Plan B pill, but may not prevent the woman from obtaining the medication elsewhere (eg by refusing to return her prescription). The Jehovah's Witness may refuse a

\footnotetext{
39 See eg <http://parentsagainstmandatoryvaccines.wikispaces.com/> for some conspiracy theories about vaccination, and the Australian government's Myths and Realities: Responding to Arguments Against Vaccination: A Guide for Providers ( $5^{\text {th }}$ edn, Department of Health and Ageing 2013).

40 Brownlee reckons this latter possibility as she argues that anti-abortion activists' appeal 'to a third-party defence for their violence... would make their position internally consistent and ceteris paribus minimally evidentially satisfactory'. But she claims that 'other anti-abortion activists would not be able to give such an account, especially when their violence is indiscriminate, ex post, or motivated by vengeance', 41 . Again, I fail to see what justifies Brownlee in drawing a line between violence that seeks to prevent future murders and ex post or retributive violence for previous murders.
} 
life-saving blood transfusion for herself, but not for her child. Similarly, the anti-immunisation parent may refuse a flu shot for himself, but should not be exempt from vaccinating his child, given the risks it imposes on the child and the disastrous cumulative effect on herd immunity, as the recent whooping cough epidemic in California demonstrates. ${ }^{41}$

Note that on Brownlee's view, lack of consistency is but one reason that certain convictions fail to be conscientious and thus do not deserve protection. They also lack conscientiousness when honouring them requires conduct that violates others' moral rights. Thus Brownlee would agree that the Jehovah's Witness parent does not deserve any protection, on the grounds that the parent's conduct violates her child's right to adequate medical care. I am not sure how she would treat the anti-vaccination parent given that it is less clear whether the parent violates his child's right to proper healthcare by refusing to vaccinate. In any case, Brownlee makes it a defining feature of conscientious conviction that it cannot require conduct that is at odds with respect for others, while my point is that we can determine which moral beliefs are entitled to protection without appealing to their conscientiousness or lack thereof.

In conclusion, there appear to be many examples of sincere moral beliefs that violate some of the criteria of the communicative principle, and yet that we have no good reason not to count among conscientious convictions. Brownlee may appeal to the context-sensitivity of the principle to show why the alleged counterexamples do not necessarily violate the standards of communicativeness, but the principle's context-sensitivity raises issues of its own, as I argued above. All in all, the foregoing discussion suggests that conscientiousness and communicativeness are different properties that should not be equated.

Keeping this distinction in mind, I would argue that the reason why the standard liberal picture is wrong is not that civil disobedience is more conscientious than personal disobedience; it is that communicativeness, not conscientiousness, is the crucial ground on which to base claims of protection. From this perspective, the morally significant difference between civil disobedients and conscientious objectors lies in the manner or form of their disobedience-the public and communicative nature of their act-rather than in the quality of the agents' motivation (their conscientiousness).

\section{Conscience}

While people with a conscientious conviction take morality seriously, on Brownlee's view, those who have conscience are 'genuinely, self-consciously morally responsive'. ${ }^{42}$ Having conscience is crucial for fulfilling our moral duties and responsibilities. However, acquiring the 'set of practical moral skills

\footnotetext{
${ }^{41}$ K Doheny, 'Unraveling the Whooping Cough Epidemic' WebMD.com <www.webmd.com/children/vaccines/ features/california-whooping-cough-epidemic > accessed 23 October 2014.

42 ibid 52 .
} 
that stem from a deep understanding of the nature of our hearts and minds' is a difficult task. ${ }^{43}$ Many obstacles can obtrude our efforts:

As [Thomas] Hill notes, we can be distracted by prevailing social norms; we can be given poor moral training as children; we can be subject to fears and prejudices or inculcated into false ideologies; we can be emotionally fragile or threatened, all of which can imitate or distort the guidance of conscience, especially if we have dulled it by frequently disregarding it. ${ }^{44}$

Though this short passage nicely evokes the numerous factors that can warp conscience, including culture, education, ideology, fear and neglect, Brownlee does not characterise these factors any further, as she is mainly interested in the kinds of errors that can occur when one tries to address a complex moral situation. ${ }^{45}$ She offers an account of what can go wrong (we may fall prey to cognitive, conative, and affective errors), but not of why things often go wrong, when we try to follow the guidance of conscience. Brownlee's account of the scope for error is very useful in helping detect one's and others' conative, cognitive and affective shortcomings in trying to act morally. But an account of the obstacles that lead to these shortcomings is logically prior to and even more important than a typology of possible errors. To cultivate conscience well, one needs to know what to beware of.

This being so, I have two main aims in the remainder of this review. First, I shall complement Brownlee's account of conscience by analysing some of the major obstacles to cultivating conscience. I will focus on those engendered by structural injustice, given its pervasive presence in decent, liberal societies, and examine in particular how erroneous convictions, when they are shaped by injustice, interfere with the development of conscience. Second, I shall identify some strategies for defusing the corrosive effects of injustice on one's moral capacities and for cultivating true conscience. In my view, one ought to exercise vigilance, self-scrutiny and empathy in daily life; and one ought to deploy constructive and collaborative ambivalence in the face of practical conflicts between one's commitments.

\section{A. Injustice}

I find the notion that the obstacles to developing conscience, which Hill and Brownlee identify, can not only distort but also imitate the guidance of conscience particularly interesting. Brownlee warns against the risks of confusing actual moral conviction with both 'asserted' moral conviction and 'morally acceptable' conviction. ${ }^{46}$ But, in my view, we should add that people are also very likely to believe they have conscience when all they have is a

\footnotetext{
43 ibid 2.

44 ibid 66, citing T Hill, Jr., Human Welfare and Moral Worth, Kantian Perspectives (OUP 2002) 284.

45 Brownlee 66-70.

46 ibid 40.
} 
conviction. The psychological and emotional investment that goes into conviction indeed makes it hard to distinguish it from conscience, especially from the first person perspective: conviction-true or false-imitates, and feels animated by, conscience.

In this section, I shall argue that structural injustice significantly impedes the development of conscience. Living under conditions of serious injustice can be unbearable and agonising. But injustice sometimes renders itself almost impalpable by convincing us that it is in fact necessary and justified-this is indeed typical of structural injustice. In my understanding, the harms of structural injustice consist in hindering some people's capacities in virtue of these individuals' perceived membership in a social group (eg ethnic or sexual minority). Under conditions of structural injustice, harms are produced primarily as a result of the 'normal' interplay between institutions, processes, and norms in society. ${ }^{47}$ These harms are therefore harder to notice than those that result from the intentional actions of individuals.

While structural injustice diminishes some people's capacities, it benefits others through privilege. On Alison Bailey's conception, privileges are 'unearned assets conferred systematically'. ${ }^{48}$ They are unearned because the members of the privileged group enjoy them as a result of sheer luck-the luck of belonging to social groups with race, heterosexual, gender or class privilege. One of the functions of privilege, according to Bailey, is to 'structure the world so that mechanisms of privilege are invisible-in the sense that they are unexamined-to those who benefit from them'. ${ }^{49}$ Privilege thus breeds blindness and blindness reinforces privilege, since being privileged is being able (even encouraged) to fail to see the oppressive system and the privileges it grants.

Privileged persons are prone to deceive themselves into thinking that they deserve their status and benefits, that they earned their gains through personal talent and effort. As privilege is invisible to the privileged person, so is oppression in general invisible to him or her (and sometimes to the oppressed themselves): the unjust situation of those who occupy a subordinated position

\footnotetext{
${ }^{47}$ See eg M Frye, The Politics of Reality: Essays in Feminist Theory (The Crossing Press 1983) ch 1; IM Young, fustice and the Politics of Difference (Princeton University Press 1990) ch 2. This broad conception of structural injustice accommodates various types of oppression. For instance, some scholars and lawyers claim that the normal workings of the US criminal justice system, with its draconian drug laws and pervasive racial profiling, lead to a 'New Jim Crow', with prison inmates disproportionately black and brown, in spite of near-identical rates of drug use and sale between whites and non-whites. See eg M Alexander, The New fim Crow: Mass Incarceration in the Age of Color Blindness (The New Press 2010). For a different example, Ann Cudd argues that by choosing to stay out of the labour market because of certain prejudices and economic forces of oppression, women in contemporary Western societies perpetuate the current sexual division of labour and wage gap. She dubs this phenomenon 'oppression by choice', since the harms of oppression come about to some degree through oppressed persons' choices. A Cudd, Analysing Oppression (OUP 2012) 146-53.

${ }^{48}$ A Bailey, 'Privilege: Expanding on Marilyn Frye's Oppression' (1998) 29 J Soc Phil 110. Bailey's definition is stipulative, distinct from the legal concept of privilege as 'legal benefit that is not a right'. The advantages she is interested in are the flipside of the harms of structural injustice (which are also systemic and unjustified). I use the term 'privilege' in Bailey's sense.

49 ibid 112.
} 
in the structure remains unseen as long as the privileges of the dominant group appear deserved. The privileged often lack basic understanding of the experience of deprivation and oppression, as well as the motivation to learn about it.

The Marxist notions of 'ideology' and 'false consciousness' further help explain how decent people can deny the existence of structural injustice without necessarily being credulous or ill willed. Ideology (understood here as a widely shared worldview that stabilises the socio-political conditions by representing them as just), and its arsenal of stereotypes and biases, assure that structural injustice remains concealed by providing a simple, alternative explanation for the disparities (often backed by appeals to race or gender essentialism). For instance, the stereotypical representation of blacks as drug users and criminals is taken to explain the disproportionate number of African Americans behind bars, thereby concealing the racist aspects of policy, law enforcement and criminal justice. ${ }^{50}$

Ideology in turn produces false consciousness. According to Tommie Shelby, 'to hold a belief with a false consciousness is to hold it while being ignorant of, or self-deceived about, the real motives for why one holds it'. ${ }^{51}$ The individual who suffers from a false consciousness believes that she accepts a belief solely because it is epistemically justified, when in reality noncognitive motives influence her belief without her awareness. Shelby gives the following examples of noncognitive motives for embracing certain beliefs:

Though presumably we do not do so consciously, we sometimes believe things because to do so would, say, bolster our self-esteem, give us consolation, lessen anxiety, reduce cognitive dissonance, increase our self-confidence, provide cathartic relief, give us hope, or silence a guilty conscience. When these and other noncognitive motives are psychologically operative, we easily fall into epistemic error. ${ }^{52}$

So not only are members of the privileged group encouraged to think that they earned their higher status, but members of the subordinated group, too, can find (unconscious) solace in the dominant ideology, for instance by believing that it is up to them to 'make it' to the top in a capitalist society. Denying structural injustice with a false consciousness can also serve as an anxiolytic against the discomforting feeling that one ought, but is not willing, to fulfil one's responsibilities in the face of injustice.

Structural injustice thus corrodes our moral capacities in the following respects: the dominant ideology, buttressed by stereotypes, infects us with bias and obstructs our reading of social reality and of our own and others' conduct. It even damages

\footnotetext{
${ }^{50}$ See Alexander (n 47).

51 T Shelby, 'Ideology, Racism, and Critical Social Theory' (2003) 34 The Philosophical Forum 170. Shelby notes that both true and false beliefs can be held with a false consciousness, so that detecting false consciousness is not sufficient for rejecting a form of social consciousness, but further requires showing the illusory content of that form of consciousness.

${ }^{52}$ ibid 172.
} 
our rational capacities, as Carol Hay has recently argued..$^{53}$ By encouraging selfdeceit, privilege and false consciousness further hinder the 'understanding of the nature of our hearts and minds' from which conscience stems. ${ }^{54}$ Conscience requires 'the cultivation of practical wisdom, generosity, attention, thoughtfulness, and compassion, ${ }^{55}$ all of which are thwarted in some ways by structural injustice: one cannot develop practical wisdom, attention and thoughtfulness, unless one is aware of society's workings and sensitive to the moral quality of one's own and others' conduct; and moral blindness typically restricts generosity and compassion to members of our own group.

Structural injustice's most enduring influence is through education, as parents and educators inculcate prejudices into children and shape their moral capacities and emotions. But it is also important to see how it is perpetuated through culture, and insinuates itself into people's convictions. Under conditions of structural injustice, erroneous beliefs and convictions that align with the dominant ideology proliferate. Some of these convictions demand conformity (eg for the staunch American patriot who believes his primary moral duty is to obey the state), while others condone noncompliance with the law (for instance, workplace discrimination against women is legitimised by sexist convictions) as well as departure from the formal dictates of one's office (think of southern states' officials' systematic failures to enforce the law under Jim Crow, in the context of white supremacist norms ${ }^{56}$ ).

These convictions spawned by injustice not only distort, but also imitate conscience, insofar as they promote a certain reading of social and moral reality, if a mistaken one, as well as a set of practical moral skills and virtues (such as assertiveness and self-reliance in a capitalist society). Moreover, we are likely to mistake these convictions for true conscience since they accord with others' and animate our cognitive and motivational responsiveness to complex moral situations (as conscience is supposed to do). Hence false convictions that result from prevailing, unjust social norms are both the virus through which injustice preserves and conceals itself and a great obstacle to cultivating conscience.

\section{B. Strategies}

Even if, as I argued above, false convictions contribute to damaging our moral capacities and perpetuating injustice, there are good reasons to think that

\footnotetext{
53 Hay offers a Kantian account of duties to oneself to resist one's oppression, which is based on the recognition of the fundamental value of our rational nature and of oppression's damaging effects on our rational and agential capacities. See C Hay, Kantian, Liberalism, and Feminism: Resisting Oppression (Palgrave Macmillan 2013).

54 Brownlee 2.

55 ibid.

${ }^{56}$ See eg CV Woodward, The Strange Career of Fim Crow (first published 1955, OUP 2001).
} 
conscientiousness is a potential antidote to the corrosive effects of injustice and thus an ally of conscience. Brownlee herself considers conviction a necessary 'precondition for integrity and conscience', though she does not say why. ${ }^{57}$ Moreover, conviction seems apt to provide protection against the toxic effects of injustice since our non-evasive and dialogic efforts should lead us to be confronted with evidence at odds with our beliefs or even with a critique of the noncognitive motives that shaped them. In this way, communicativeness may be thought to expose us to exactly the kind of scrutiny that will weed out erroneous beliefs.

However, there are certain reasons to doubt this effect of communicativeness. First of all, people tend to associate with people like themselves, who have similar worldviews, making the chances that one's erroneous convictions will be critiqued in a dialogic setting actually quite low. Scholars have argued that this effect-surrounding ourselves with like-minded people who will confirm our convictions-is amplified online as a result of Google's 'personalised' searches, whereby 'Google directs you to material that is most likely to reinforce your own worldview, ideology, and assumptions' ${ }^{58}$ Besides, as I mentioned above, one's erroneous convictions are likely to be shared by much of society under conditions of structural injustice anyway. Finally, as Shelby notes, '[i]t is a salient fact about certain illusory forms of consciousness that those who hold them often continue to be under their spell even after they have been subjected to a number of telling, sometimes devastating, criticisms'. ${ }^{59}$ Resistance to ideology critique is the default position for convictions shaped by injustice and held with a false consciousness.

For all these reasons, we should be cautious about the potential of conscientiousness to remedy the corrosive effects of injustice. Instead, as I will now argue, we ought to cultivate a set of attitudes as we try to respond to complex moral situations: vigilance, self-scrutiny, empathy, and collaborative ambivalence.

First, we have a responsibility to do our best to see things as they actually are, which includes a responsibility to seek out information. Becoming aware of structural injustice requires acute awareness to one's surroundings, which is difficult given the common failure to question the existing arrangements. Critical thinking is crucial to the task, including questioning tradition and prevalent beliefs. Different venues may promote this type of scrutiny, including

\footnotetext{
${ }^{57}$ Brownlee $42 \mathrm{n} 40$. Brownlee cites Matthew Pianalto's arguments as to why 'discourse' is a crucial feature of 'responsible moral conviction' from M Pianalto, 'Moral Conviction' (2011) 28 J App Phil 381. But the arguments she sets forth in this footnote don't warrant the claim that conviction is a precondition for conscience.

${ }_{58}$ S Halpern, 'Mind Control \& the Internet' The New York Review of Books (23 June 2011), reviewing E Pariser, The Filter Bubble: What the Internet is Hiding from You (Penguin 2011).

${ }^{59}$ Shelby (n 51) 171.
} 
interactive environments such as campuses and community centres, consciousness-raising workshops, and diversity and inclusion projects. ${ }^{60}$

Second, we have a general responsibility to resist self-deception. Recall Shelby's explanation of false consciousness:

We sometimes believe things because to do so would, say, bolster our self-esteem, give us consolation, lessen anxiety, reduce cognitive dissonance, increase our selfconfidence, provide cathartic relief, give us hope, or silence a guilty conscience. ${ }^{61}$

Avoiding the influence of the variety of noncognitive motives that can lead us into false consciousness involves self-scrutinising and resisting self-centeredness, resentment, deception and self-pity. The task is arduous, and requires keen perception and courage. ${ }^{62}$

Third, we must do our best to understand other people. The right kind of understanding involves empathy and care, and really learning about the experience of one another. Laurence Thomas argues in particular that the privileged must listen to the oppressed with a certain attitude he calls 'moral deference' and which involves openness and attentiveness. ${ }^{63}$ According to Elizabeth Spelman, the privileged must exercise their imaginative capacities to put themselves in the shoes of the oppressed. ${ }^{64}$ Imaginative self-projection, empathy, and self-awareness are thus required for proper moral learning. ${ }^{65}$

Erroneous convictions that are spawned by injustice get in the way of all three attitudes: they hinder accurate perception of social reality, breed selfdeception, and block the paths of proper moral learning. However, the attitudinal responsibilities I advocate above counsel vigilance toward one's cherished, deeply held convictions, since they may turn out to be nothing but entrenched biases. Hence these attitudes may be the real or most important preconditions for conscience and integrity. Someone who does not even try to cultivate them may be blamed for his or her failure. According to John Draeger, for instance, indifference and failure to care about victims of oppression are morally blameworthy, as they amount to denying the victims' basic moral worth as human beings. ${ }^{66}$

A fourth attitude is conducive to cultivating conscience in cases of practical conflicts between commitments. Brownlee broaches such conflicts within her discussion of the consistency condition. She suggests a 'context-sensitive

\footnotetext{
${ }^{60}$ See eg The National SEED Project on Inclusive Curriculum ${ }^{\mathrm{SM}}<$ www.nationalseedproject.org/about-us $>$. SEED (Seeking Educational Equity \& Diversity) aims to create 'gender fair, multiculturally equitable, socioeconomically aware, and globally informed education' by engaging educators, parents, and community leaders. It is the nation's largest peer-led leadership development project.

${ }^{61}$ Shelby (n 51).

${ }^{62}$ See eg A Garrett, 'Courage, Political Resistance, and Self-Deceit' (2010) 90 BU L Rev 1771.

${ }^{63}$ LM Thomas, 'Moral Deference' in C Willet (ed), Theorizing Multiculturalism (Blackwell 1998) 359-81.

${ }^{64}$ EV Spelman, Inessential Woman: Problems of Exclusion in Feminist Thought (Beacon Press 1988) 179.

${ }^{65}$ See SL Bartky, Sympathy and Solidarity and Other Essays (Rowman \& Littlefield, 2002); J Harvey, 'Moral Solidarity and Empathetic Understanding' (2007) 38 J Soc Phil 22.

${ }^{66}$ J Draeger, 'Must We Care About Racial Injustice?' (2008) 39 J Soc Phil 62.
} 
approach to how we privilege different commitments in action', so as not to run afoul of the requirement of consistency. ${ }^{67}$ According to this approach, a given commitment may be salient in context 1 , but not in context 2 , where another commitment is salient. In Brownlee's example, a woman committed to covering her head in public needs to go out bareheaded to get aid for her sick child; however, only other women will see her. Since her commitment to her child's welfare is the most salient feature of the situation (given the child's sickness), and insofar as 'it is not a core part of [her] conviction that women not see [her] bareheaded', the woman's seeming lapse of consistency is a merely apparent one, and by no means undermines her conscientious commitment to covering her head. ${ }^{68}$

Of course Brownlee recognises that such straightforward solutions are not always available, noting in particular that although the woman's conduct satisfies the consistency condition in the imagined scenario, ' $[\mathrm{t}]$ he more rigid, absolute, and demanding your declared conviction is, the less easily you can adopt a context-sensitive approach to consistency'. ${ }^{69}$ However, she does not further explore the parameters of, and possible approaches to, practical conflicts. In the remainder of this review article, I shall suggest that certain forms of ambivalence, in the face of conflicts between commitments, are particularly propitious to developing true conscience.

Ambivalence appears to stand opposed to the idea of 'clean conscience', which Brownlee understands, along the lines of the Buddhist notion of 'bliss of blamelessness', to designate 'the happiness that comes from leading a life of objective integrity as well as we can'. ${ }^{70}$ If 'clean conscience' refers to moral ease, ambivalence seems rather the mark of a troubled, confused, or 'unclean' conscience, one whose inner conflicts undermine steadfast responsible action.

However, Amelie Rorty has recently pleaded in favour of ambivalence, arguing that it can be epistemologically grounded and responsible, and that constructive and collaborative resolutions of ambivalence reveal how much of our thinking - and so also how much of our motivational structure-emerges from the details of our collaborative and dialogical engagements'. ${ }^{71}$ Rorty conceives of ambivalence as 'one of the costs of the latent tensions among the competing priorities of our multiple identifications and allegiances'. ${ }^{72}$ In other words - and consistently with Brownlee's commitment to moral pluralismambivalence is inevitable given the multiplicity of roles we inhabit. 'We are all (in one way or another) Methodist-Cambodian-American-entrepreneurialacademic-Red Sox-fans-in-debt', writes Rorty: 'we absorb and internalize the

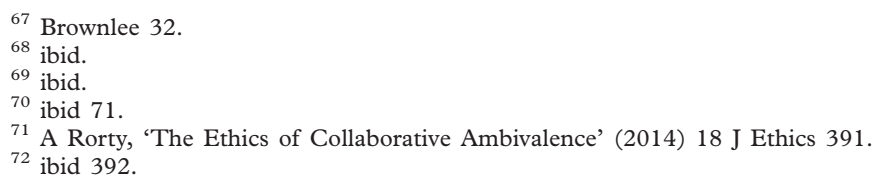


ethos of diverse modes of life whose organizing values and priorities are in practice sometimes incompatible and incommensurable'. ${ }^{73}$

Rorty distinguishes ambivalence from indecisiveness and vacillation. When we are indecisive about what to do, we are in a maybe this/maybe that epistemic condition, with multiple distinctively ranked preferences among their various desirable options'. ${ }^{74}$ We vacillate when we are 'in a now this/now that epistemic condition that expresses erratic and shifting preferences between distinctive and apparently incompatible options' ${ }^{75}$ To be ambivalent is to be 'in a both/and epistemic and motivational condition, endorsing all one's options while thinking them incompatible'. ${ }^{76}$ Whereas indecision and vacillation call for stable guiding criteria, which we can arrive at by engaging in reflective equilibrium, the best policy in the face of ambivalence, according to Rorty, involves first trying to identify and assess the sources and grounds of our ambivalence.

When we have reasons in favour of each alternative, so that our ambivalence is a fitting response to our circumstances, Rorty deems our ambivalence internally appropriate. ${ }^{77}$ If we reflectively attempt to integrate the grounds for our appropriate ambivalence with our other commitments, we are responsibly ambivalent. ${ }^{78}$ We can also imaginatively reframe our choice in order to preserve the terms and rationales of both commitments, thereby exercising constructive ambivalence. ${ }^{79}$ The best strategy for constructive ambivalence involves expanding the scope of our partners in deliberation and enlisting their empathic cooperation in a shared deliberative effort. Collaborative ambivalence, as Rorty calls this, enables us to envision different resolutions to our conflict as well as to deepen our understanding of ourselves and our partners through practical and dialogic engagement with others. ${ }^{80}$

Rorty draws several conclusions from her discussion. First, the strategies of collaborative ambivalence should be deployed to address conflicts in both the private and public spheres. ${ }^{81}$ Second, the rich imaginative skills involved in constructive, collaborative ambivalence should count among our civic virtues and be fostered accordingly through education. ${ }^{82}$ Third, reflection on the ethics of ambivalence reveals the deeply collaborative structure of our thinking, contra 'our folk-psychological and philosophical models of thoughtful deliberation... [which] treat thinking as an individualistic process' ${ }^{83} \mathrm{I}$ am particularly interested in this last point and how it relates to Brownlee's conception of conscience.

\footnotetext{
73 ibid.

74 ibid 394.

75 ibid.

76 ibid.

77 ibid 395.

${ }^{78}$ ibid 396-97.

79 ibid 399.

80 ibid 399-402.

81 ibid 392.

82 ibid 392, 401.

${ }^{83}$ ibid 392.
} 
Through education, we learn from someone else to cultivate the practical moral skills required for true conscience; we form our convictions under the influence of others; we learn our roles and responsibilities with others; we try to be responsive to the needs of others; and we also continually transform ourselves by practically engaging with others. In short, conscience is an interactive enterprise, which we learn and undertake with others.

Brownlee's communicative principle may seem to hint at the collaborative nature of conscientious and conscience-animated thinking, given its requirement to engage in dialogue with others about one's views. But being willing to give a reasoned defence of one's view is not the same thing as cooperating with others to adjust one's view to new and complex moral situations. Brownlee later identifies three sources in which solutions to practical dilemmas can be found-the democratic decision-making process, the consensus of the relevant office-holders, and a coordination principle - all of which emphasise collaborative engagement of some sort. ${ }^{84}$ However, she finds these conflict-resolution procedures flawed and limited and does not discuss non-institutionalised collaborative resolutions.

Upon closer reading, Conscience and Conviction may be found to construct one of those philosophical models that treat thoughtful (conscientious and conscience-driven) deliberation as an individualistic process. This is visible at various points, starting with the book cover's illustration from Norman Rockwell's The Fury, in which a woman stands firm in her conviction, alone against eleven men $^{85}$ (and yet the jury room could provide an interesting model of collaborative ambivalence). It is also manifest when Brownlee refers to individual paragons of conscience such as Aung San Suu Kyi ${ }^{86}$ and the Dalai Lama ${ }^{87}$ (who certainly engage in dialogue with others, but perhaps more as teachers or mediators than as partners in deliberation), as well as with the notion of 'bliss of blamelessness, ${ }^{88}$ which indeed can only bless a select few individuals. Brownlee's individualistic slant appears more generally in her discussion of the moral roles thesis, in which she emphasises the responsibility to think for ourselves against our peers and superiors in order to privilege our moral responsibilities before the formal expectations of our positions when these conflict non-trivially. ${ }^{89}$

These individualistic accents inflecting Brownlee's book together suggest that her model of conscience misses, and should have included, the crucial insight brought out so vividly by Rorty regarding the collaborative nature of our thinking.

Collaborative ambivalence seems like an especially fitting strategy to resolve some of the practical conflicts facing professionals. Brownlee praises the doctors

\footnotetext{
${ }^{84}$ Brownlee 116-17.

${ }^{85}$ Brownlee reflects on the painting in two different passages: ibid 1-2, 11. She also discusses it at length in her interview with Robert Talisse for New Books in Philosophy (28 May 2013) <http://newbooksinphilosophy.com/ 2013/05/28/kimberley-brownlee-conscience-and-conviction-the-case-for-civil-disobedience-oxford-up-2012/> accessed 25 July 2014.

${ }^{86}$ ibid $32,51,64,71,74,77,81,85-86$.

87 ibid 39, 76.

88 ibid 71 .

${ }^{89}$ ibid 87-88, 97-100.
} 
in California who refused to oversee capital punishment by lethal injection, leading to a de facto moratorium on executions in the state. However, physicians' and anaesthesiologists' conscientious opposition to overseeing capital punishment does not necessarily halt executions; instead it often leads to their performance without properly trained staff. This regularly results in patientinmates' extreme and prolonged suffering at the time of death, as the recent botched executions in Ohio, Oklahoma, Arizona, and Arkansas illustrate. ${ }^{90}$

So physicians might feel appropriately ambivalent about their role-based responsibilities in the situation, torn between their dedication to preserving life and their duty to alleviate patients' suffering. Physicians appropriately and responsibly ambivalent about what to do in cases of capital punishment would attempt to assess the sources of their ambivalence. They would reflect on their special moral responsibilities as healthcare providers in the particular political context (eg given the state's commitment to executing convicted defendants with or without medical staff), and not just in the abstract (eg by merely invoking the Hippocratic oath to 'do no harm' ${ }^{\prime 91}$ or the immorality of capital punishment ${ }^{92}$ ). Constructive ambivalence also calls for enlisting the whole profession to reflect on the dilemma. The American Medical Association (AMA) and the American Society of Anaesthesiologists (ASA), for instance, issued official statements against physician participation in executions. ${ }^{93}$

Collaborative ambivalence may thus be crucial not only for individuals to find a solution to the conflicts they face, but also to realising the minimum moral burdens principle in society. According to this principle, society must ensure as well as possible that the offices it sets up to address important concerns do not place undue moral burdens upon any would-be occupants of those offices. ${ }^{94}$ The results of professionals' shared deliberation can indeed guide society in its attempt to minimise the moral burdens that befall roleoccupants in cases of conflicts between the formal expectations of offices and the moral responsibilities that underpin and legitimate those offices. Thus the American Board of Anaesthesiologists (ABA) sanctions anaesthesiologists who

\footnotetext{
${ }^{90}$ See eg G Strauss, 'Ohio Killer's Slow Execution Raises Controversy' USA Today (16 January 2014) <www. usatoday.com/story/news/nation/2014/01/16/ohio-killer-executed-with-new-lethal-drug-combo/4512651/> accessed 17 October 2014; CJ Carter and J Morris, 'Documents: Not Enough Drugs Left to Finish Botched Oklahoma Execution' CNN (8 September 2014) <www.cnn.com/2014/05/01/us/oklahoma-botched-execution/> accessed 15 October 2014; 'Botched Execution: Arizona Prisoner Takes Two Hours to Die' The Week (24 July 2014) <www. theweek.co.uk/us/58333/botched-execution-why-us-has-turned-untried-drugs $>$; M Brantley, 'A Botched Execution Doesn't Appear to Stir Much Discussion in Arkansas' The Week (5 May 2014) <www.arktimes. com/ArkansasBlog/archives/2014/05/05/a-botched-execution-doesnt-appear-to-stir-much-discussion-in-arkansas > accessed 17 October 2014 .

91 See eg AMA, Code of Medical Ethics, 'Opinion 2.06-Capital Punishment' <www.ama-assn.org/ ama/pub/physician-resources/medical-ethics/code-medical-ethics/opinion206.page?> accessed 1 October 2014.

${ }_{92}$ See eg PJ Litton 'Physician Participation in Executions, The Morality of Capital Punishment, and the Practical Implications of Their Relationship' (2013) 41 JL Med \& Ethics 333.

93 AMA (n 91); ASA, 'Statement on Physician Nonparticipation in Legally Authorized Executions' (approved 2006, reaffirmed 2011) <www.asahq.org/For-Members/ /media/For\%20Members/Standards $\% 20$ and $\% 20$ Guidelines/2012/STATEMENT\%20ON\%20PHYSICIAN\%20NONPARTICIPATION\%20IN\%20LEGALLY. ashx $>$ accessed 29 October 2014 .

${ }^{94}$ Brownlee 88, 100-2.
} 
participate in legally authorised executions by revoking their ABA Certification. ${ }^{95}$ In so doing, the ABA seeks to eliminate one course of action for anaesthesiologists (namely, participation) and, in effect, transfers the dilemma onto authorities, as the latter are now caught between the Scylla of botched executions as a result of lack of expert oversight and the Charybdis of imposing excessive burdens on physicians by requesting, or even mandating, their presence, as some states do. ${ }^{96}$ In these ways, collaborative ambivalence helps redescribe the binary choice facing physicians between participating or not participating, by transferring some of the pressure onto state authority and initiating debates about the special moral responsibilities of healthcare providers and what the state can legitimately ask of them.

\section{Conclusion}

In conclusion, this review challenged Brownlee's conceptions of the two core concepts of the book - conscience and conviction. I first argued that Brownlee's understanding of conscientious conviction as necessarily communicative is too narrow. It arbitrarily excludes core moral beliefs such as faith-based religious beliefs, burgeoning moral commitments, and dissident political views, which we would want to classify as convictions although they violate one or more of the conditions of the communicative principle (insofar as they are not consistent, evasive, universal, or dialogic). Although Brownlee responds to a number of objections in the book, her emphasis on the communicative principle's context sensitivity seems to defeat the force and point of the principle, which is to ensure that the sincerity of our commitments be clearly visible to all. In addition, the communicative principle draws problematic lines between beliefs that are responsive to basic evidentiary standards, and thus satisfy the consistency requirement, and those that violate such requirement. In lieu of equating conscientiousness and communicativeness, I proposed to keep the two properties separate while defending the case for respecting suitably constrained civil disobedience in virtue of its communicativeness.

Second, I argued that Brownlee's conscience argument rests on an incomplete account of conscience, insofar as it neglects some of the persistent obstacles for the cultivation of conscience. I identified those obstacles produced by structural injustice and proposed several strategies for developing conscience against them, including vigilance, self-scrutiny, empathy, and collaborative ambivalence. Reflection on the latter strategy further helps to perceive the

\footnotetext{
${ }^{95}$ ABA, Primary Certification Booklet of Information, 3.06 'Professional Standing' (February 2014) <www. theaba.org/pdf/BOI.pdf $>$ accessed 28 October 2014. As far as I can tell, no anaesthesiologist's license has been revoked, in part because participating doctors are generally granted anonymity.

${ }_{96}$ Oklahoma is one of those states. See eg AMA, 'State Mandates for Physician Participation in Capital Punishment Violate Medical Ethics’ (2 May 2014) <http://www.ama-assn.org/ama/pub/news/news/2014/201405-02-state-mandates-capital-punishment.page > accessed 29 October 2014.
} 
collaborative nature of both conscientious and conscience-driven thinking and to grasp the potential of shared deliberation in cases of professional dilemmas.

My disagreements with Brownlee aside, Conscience and Conviction is an outstanding book that any scholar working on civil disobedience, conscientious objection, punishment, and practical reason, ought to engage with. The book's merits lie not only in the rich and nuanced answers it offers to important questions, but also in its ability to raise new questions and stimulate engaging philosophical discussion. 